\title{
Regional and Monthly Assessment of Possible Sunshine Duration in Pakistan: A Geographical Approach
}

\author{
Romana Ambreen1, Iftikhar Ahmad1, Xinfa Qiu², Menjei Li² \\ ${ }^{1}$ Department of Geography, University of Balochistan, Quetta, Pakistan \\ ${ }^{2}$ Nanjing University of Information Science and Technology, Nanjing, China \\ Email: iftigeog@gmail.com
}

Received 25 January 2015; accepted 21 February 2015; published 25 February 2015

Copyright (C) 2015 by authors and Scientific Research Publishing Inc.

This work is licensed under the Creative Commons Attribution International License (CC BY). http://creativecommons.org/licenses/by/4.0/

c) (i) Open Access

\section{Abstract}

The monthly possible sunshine hours have been simulated separately for all the months of the year with the help of ArcGIS. The results are evident that the geography of the area plays a pivotal role in giving shape to spatial distribution of monthly possible sunshine duration (PSD). The landforms distributions and latitudinal extent are the major geographical factors behind the spatial-temporal distribution of monthly PSD. Maps of all the months depict different sunshine hours that vary from region to region in Pakistan. The maximum difference in PSD was noticed between lofty mountains in the north and Indus Plains. In addition, the variation is phenomenal from January to August and vice versa. This sort of study based on spatial modeling is significant in Pakistan where we lack appropriate ground observed data of PSD.

\section{Keywords}

Pakistan, Possible Sunshine Duration, Monthly, GIS, Landforms Impact

\section{Introduction}

In Pakistan, solar energy and its application can be the main subject in near future, because Pakistan is densely populated with its main stay on agriculture and always facing acute shortage of energy needed for sustainable economic development. Substantial area of Pakistan is dominated by mountains and hills; the life and economy in the plains are directly or indirectly connected with these areas as most of the upper catchments of small and large rivers get water from these rugged lands.

PSD received at the ground depends on astronomical and geographical factors. We receive solar irradiance as 
the sun shines above the horizon. The PSD is considered as maximum possible sunshine duration that can occur between sunrise and sunset times for a particular locality. The PSD is defined as its astronomical analog and geographic counter part with no atmospheric influence and only terrain intershielding is taken into account on its spatial distribution [1]. The daily PSD varies from locality to locality in rugged lands due to height, aspect and the obstruction created by the landforms in immediate surroundings [2]. The slopes aspects that positioned opposite to solar irradiance can not see sunrise (earlier) or sunset (later) than the plains [3]-[5]. Therefore, the hill shadows intensely influence the surface solar energy balance in rugged parts [6] [7]. The terrain screening impact on sunshine duration stands significant because it affects the total amount of sunshine duration received at any particular point or geographical locality [8].

The application of DEM is extremely useful in geospatial sciences for studies in difficult and inaccessible terrains [9]-[13]. In the diversified lands of Pakistan, the scientific discussion on only solar analogue is not enough, and the surface geographical parameterization needs to be paid attention [14]. The data situation in Pakistan is not satisfactory like low stations density and their sparse spatial distribution, little or no solar radiation data, non satisfactory sunshine hour data, and low quality of ground observed cloud cover data therefore, in this situation the estimation of monthly PSD through spatial modeling based on GIS could be an appropriate choice. Hence, GIS in combination with DEM is a powerful tool if appropriately applied in Climate and mountain sciences [15] [16].

\section{Methodology}

Location, direction and altitude of the landforms is important in PSD of a place to be estimated, therefore, the responding impact of landforms on the PSD is changing as the position of the sun changes in the sky therefore, the daily PSD varies from point to point. The landform detail of the study area was retrieved from SRTM released by NASA, with resolution of 30 Arc second (equals to $1 \mathrm{~km} \times 1 \mathrm{~km}$ ) SRTM-GTOPO30 product corrected by GTOPO30. The data tiles in GeoTiff format can be easily processed in ArcGIS platform. Following are the basic principle of the model.

On any solar day, the PSD for point $P$ has direct relation with sun's elevation angle, azimuth and inter-shielding impact of landforms. Hence, point $P$ will get exposure to the sun, if the sun elevation angle $\left(h_{i}\right)$ is more than the aspect angle otherwise not. By taking time step length $(\Delta T)$, the daily PSD may be measured by the corresponding sun hour angle $\Delta \omega$ (in radians), now tit become easy to split the time period between sunrise and sunset times for a horizontal plane. Therefore the shielding impact $\left(S_{i}\right)$ caused by landforms for the point $P$ is dependent on direction of $\Phi_{i}$, sun elevation angle $h_{i}$, as well as elevation of the terrain. If the point $P$ is exposed to the sun, and the shielding impact $\left(S_{i}\right)$ from adjacent elevations $S_{i}=1$, otherwise $S_{i}=0$ and shields point $P$. practically the landforms with different elevations are depicted by construction of DEM consists of discrete units and determines the spatial resolution.

Reference to $P$ as the starting point and consider $\Delta L$ as the space step length, the stepwise screening of terrain elevations at point $P$ is determined. The number of Calculations $(\mathrm{N})$ is dependent on the screening radius $R$. The radius $R$ was taken $50 \mathrm{~km}$ which can meet the demand of necessary calculations and the time step length $\Delta \mathrm{T}$ equals to 10 minutes. By applying appropriate, resample methods like the nearest neighbor interpolation, bilinear interpolation and double cubic convolution interpolation (Zhang, 2000). The nearest neighbor interpolation resample was found highly efficient but with low precision and double cubic convolution interpolation was perceived with highest precision but low efficiency. Thus keeping in view the $n+1$ time interval the two adjacent times can take the form of one interval leading to $i$ intervals. Now suppose that the screening coefficient for each of the intervals can be obtained as,

$$
g_{i}=\frac{1}{2}\left(S_{i}-1+S_{i}\right)
$$

Conclusively, the PSD (in hours) on any of the solar day for the point $P$ on rugged terrains can be given by

$$
T=\frac{24}{2 \pi}\left[\sum_{i=1}^{n-1} g_{i} \Delta \omega+g_{n} \bmod \left(\frac{2 \omega_{o}}{\Delta \omega}\right)\right]
$$

For more technical detail read [17].

The simulated results are shown for each month of the year that displays the characteristics of PSD in Pakistan at sub-regional level. In winter months (e.g. January) the solar declination angle $(\delta$ ) remains negative, being 
in subtropical region Pakistan receives oblique solar radiation where the low sun angle results into less PSD and more intershielding impact of landforms and vice versa in summer part (e.g. June \& July) of the year. The physical map Figure 1 has the required detail of landforms and location of places in the study locus. Results are shown in Figure 2 based on PSD at monthly scale with $1 \mathrm{~km} \times 1 \mathrm{~km}$ resolution over the rugged lands of Pakistan.

\section{Results and Discussion}

In January the low angle of the sun persists therefore comparatively less PSD are obtained in Pakistan. The low angle also encourages more shielding impact of landforms. A distinct variation of PSD between the plains and mountains has been observed. The southern, central and northern parts of the country have obvious variations in PSD from south (north) to north (south) during the journey of twelve months in a solar year. The southward slopes are receiving quite ample solar radiation in term of duration than the northward facing slopes. In Pakistan, at regional level the trend of mountains vary and creating complex relationship between slopes aspect and PSD. The most obvious variation was noticed in the HKH region, this region is not only in the northern parts of the country but the region is also custodian of the highest mountains. The PSD is increasing from January to June and July, and vice versa. There is little difference of PSD per unit area in plains but the major difference lies in the mountains. With the shift from winter months to summer months, the belt of maximum PSD is shifting northwards in the country. The country like Pakistan portrays maximum difference of PSD between southern and northern territories due to sufficient north-south latitudinal extension. The Kirthar, Brahui and Makran ranges did not show that much filtering impact on PSD as shown by HKH Mountains. The factors behind are, that first said ranges are in the south and additionally there height is less than HKH.

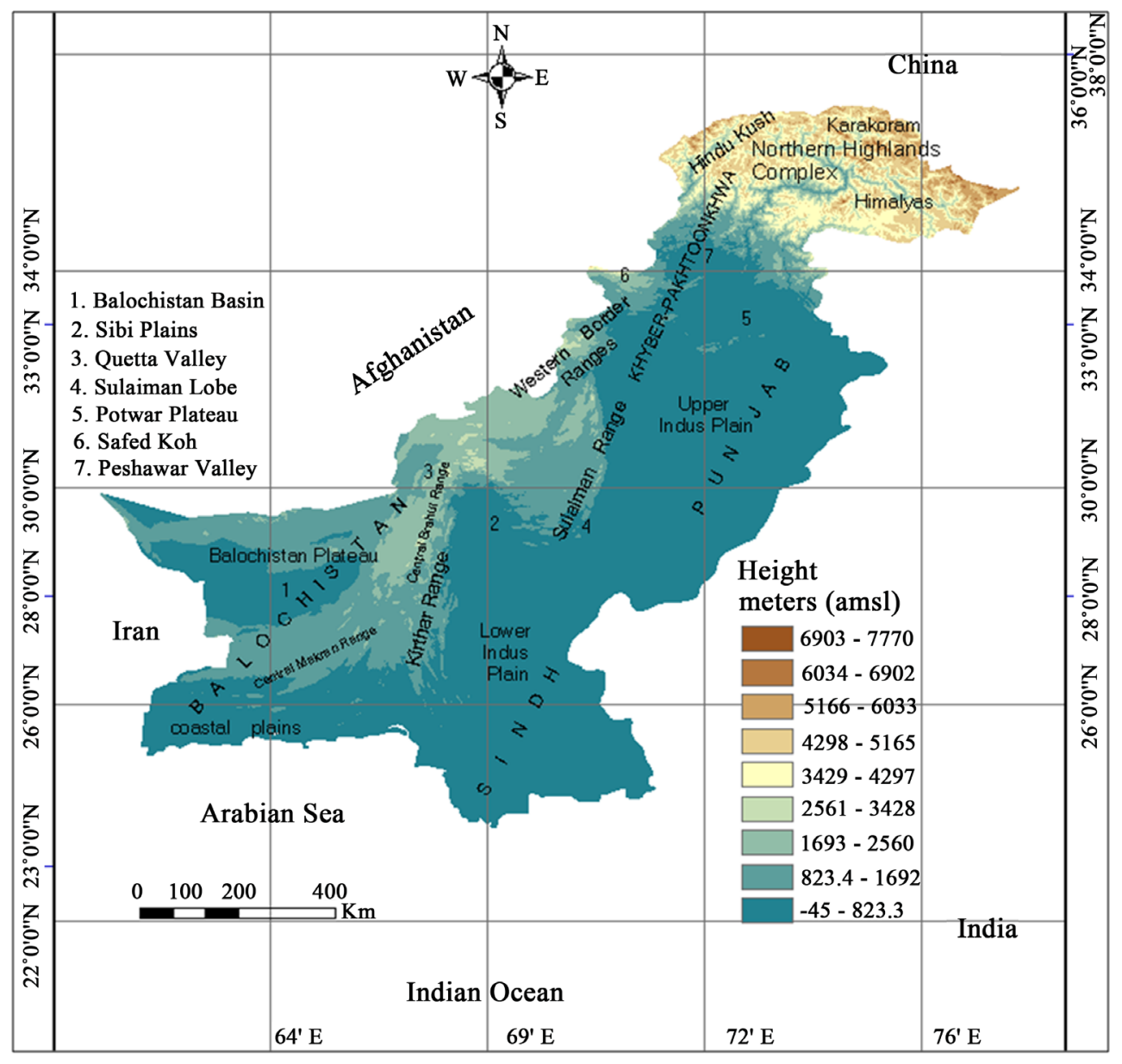

Figure 1. Pakistan's location, relief and detail of localities in the study area. 

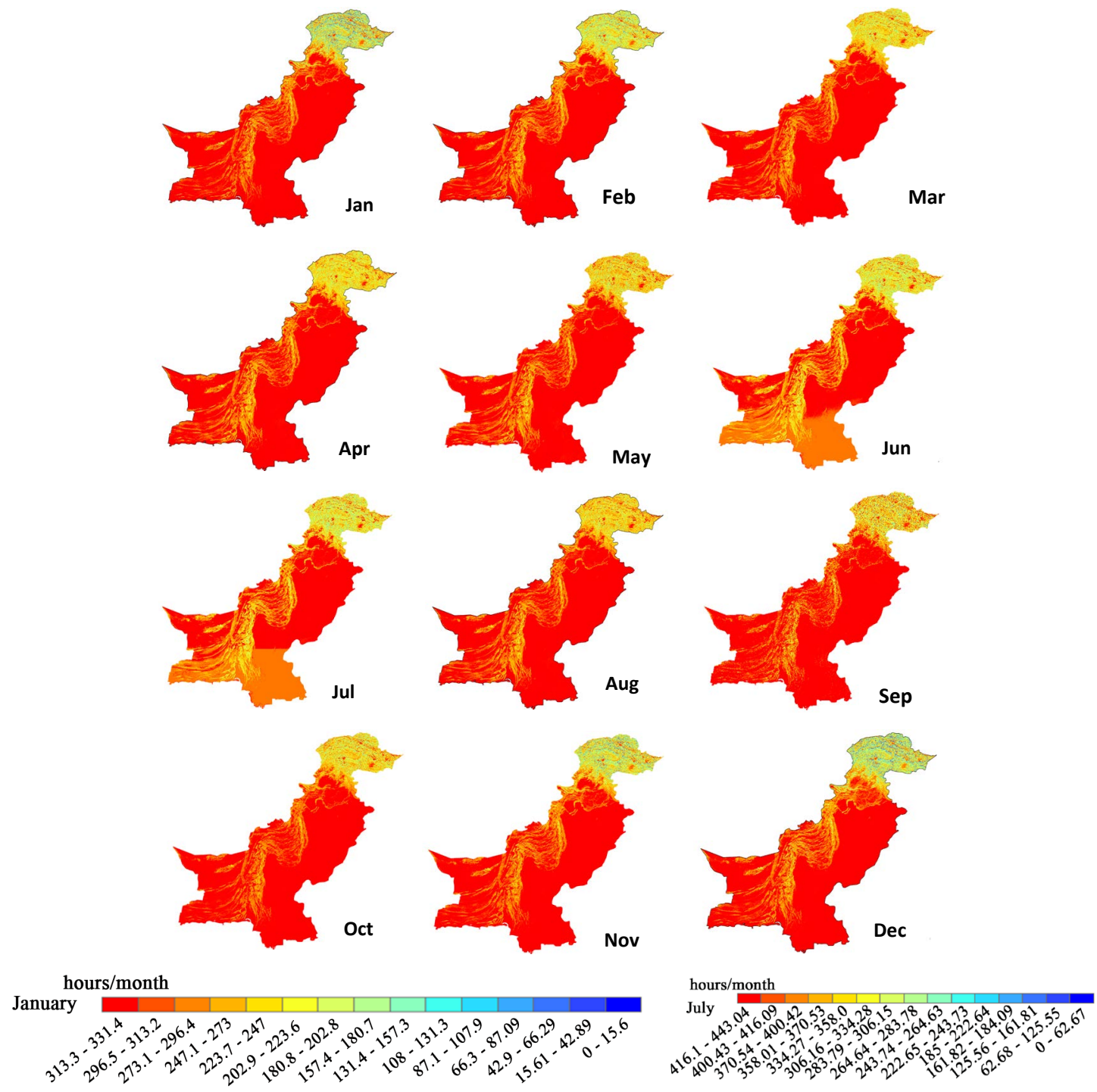

Figure 2. The Figure shows the possible sunshine duration for all the months of the year in Pakistan. The key at the bottom of the Figure is given for January and July; it works for the rest of the months also because their range of possible sunshine hours lies between January (minimum) and July (maximum).

Based on results in January, 297 - 331 are the maximum possible monthly hours (mh) in most of the plains while from 201 to $266 \mathrm{mh}$ in the Kirthar, Makran, Brahui, Sulaiman, Waziristan ranges, however some high northern aspects in mountains show difference. Few patches indicate southward slopes with maximum mh (above 298) in HKH while the rest of HKH region mostly shows 0 - 266 mh of PSD. In February, many slopes partially came under sunshine located in Kirthar, Makran, Brahui, Sulaiman, Waziristan ranges as the sun declination angle increased. Consequently, the maximum hour patches also increased in HKH. In March, the maximum PSD belt raised across Peshawar valley at the foot of the Hindukush Mountains. Steadily the southern slopes that display maximum hours became more obvious than they were in February. Monthly PSD is about 346 to $368 \mathrm{mh}$ mostly in the plains and minimum hours $(0-48 \mathrm{mh})$ were found in $\mathrm{HKH}$ on the northward slopes.

Reference to April, we have substantial increase in PSD especially in the plains. Here the HKH region is good indicator of change. The PSD patches on the southern slopes and parts of valleys that receive sunshine have increased in size. It is also clear that the filtering effect exerted by shadow impact has been lessened in Kirthar, Makran, Brahui, Sulaiman and Waziristan ranges. Moreover, this impact is further decreased in the months of May and June. The enclosed valleys in Quetta region and Sulaiman ranges now have the PSD more or less the 
same as in the plains. The maximum PSD patches have risen up in the mountains north of Peshawar valley. The PSD has increased up to about 396 - 443 mh in the plains, and 257 - 256 in Kirthar, Makran, Brahui and Sulaiman ranges. The maximum PSD zone in June has shifted further north and another zone became obvious in the southern Balochistan and Sindh characterized by 356 - 400 mh of PSD. In July up to 412 - 444 are maximum hours recorded in the plains however, June and July seems to be more or less analogous. In both June and July, the maximum area in the complex rugged zone of HKH is exposed to PSD. Keen observation shows that the retreat of PSD has commenced in August, September, October and reaches up to minimum level in December and January. Side by side the screening effect of landforms become more effective, first that could be seen in HKH region followed by relief in the vicinity of Peshawar valley, Waziristan hills, Sulaiman ranges, Brahui, Kirthar and Makran ranges.

\section{Conclusions}

By making use of DEM input into ArcGIS based on distributed modeling, the monthly PSD has been mapped. The simulated results found are in accordance with geographical realities of the study area. The intershielding impact of landforms on the spatial distribution of PSD has been captured by the results appropriately; especially it is robust in HKH region. This sort of study could be a new possibility for the scientific investigation in agrobased society living in subtropical region with ample hours of sun shining.

PSD has great relation with ground temperature and shape the evapotranspiration balance of the area too, so it has great implication in agriculture. The study could be helpful if linked with melting of glaciers in the HKH region. The study could also be linked with the micro ecosystems persist on the northern and southern slopes of $\mathrm{HKH}$. The study can also be handy in temperature variability in rugged parts of Pakistan. The relation of vegetation cover and PSD could be of great interest in Pakistan.

\section{Acknowledgements}

After the inductions of anonymous reviewer's comments, the paper has been improved further.

\section{References}

[1] Li, Z.Q. and Weng, D.M. (1988) A Computer Model for Calculating the Duration of Sunshine in Mountainous Areas. Chinese Science Bulletin, 33, 1624-1626.

[2] Li, X., Cheng, G.D., Chen, X.Z. and Lu, L. (1999) Modification of Solar Radiation Model over Rugged Terrain. Chinese Science Bulletin, 44, 1345-1349. http://dx.doi.org/10.1007/BF02885977

[3] Weng, D.M., et al. (1981) Microclimate and Its Applications to Farmland. Agriculture Press, Beijing, 116. (In Chinese)

[4] Qiu, X.F., Zeng, Y. and Liu, S.M. (2005) Distributed Modeling of Extraterrestrial Solar Radiation over Rugged Terrain. Chinese Journal of Geophysics, 48, 1100-1107. http://dx.doi.org/10.1002/cjg2.753

[5] Qiu, X.F., Zeng, Y., Liu, C. and Wu, X. (2004) Simulation of Astronomical Solar Radiation over Yellow River Basin Based on DEM on Rugged Terrain of the Yellow River Basin. Journal of Geographical Sciences, 14, 63-69. http://dx.doi.org/10.1007/BF02873092

[6] Essery, R. (2004) Statistical Representation of Mountain Shading. Hydrology and Earth System Sciences, 8, 10451050 .

[7] Kumar, L., Skidmore, A.K. and Knowles, E. (1997) Modeling Topographic Variation in Solar Radiation in a GIS Environment. International Journal for Geographical Information Science, 11, 475-497. http://dx.doi.org/10.1080/136588197242266

[8] Li, Z.Q. and Weng, D.M. (1988) The Distribution and the Computing Model of the Diffuse Radiation on Slopes. Acta Mctcorologica Sinica, 46, 349. (In Chinese)

[9] Wilson, J.P. (2012) Digital Terrain Modeling. Geomorphology, 137, 107-121. http://dx.doi.org/10.1016/j.geomorph.2011.03.012

[10] Zeng, Y., Qiu, X.F., Liu, C. and Jiang, A. (2005) Distributed Modeling of Direct Solar Radiation on Rugged Terrain of the Yellow River Basin. Journal of Geographical Sciences, 15, 439-447. http://dx.doi.org/10.1360/gs050407

[11] Dozier, J. and Frew, J. (1990) Rapid Calculation of Terrain Parameters for Radiation Modeling from Digital Elevation Data. IEEE Transactions on Geoscience and Remote Sensing, 28, 963-969. http://dx.doi.org/10.1109/36.58986

[12] Dozier, J. and Qutcalt, S.I. (1979) An Approach toward Energy Balance Simulation over Rugged Terrain. Geographi- 
cal Analysis, 11, 65-85. http://dx.doi.org/10.1111/j.1538-4632.1979.tb00673.x

[13] Pons, X. and Ninyerola, M. (2008) Mapping a Topographic Global Solar Radiation Model Implemented in a GIS and Refined with Ground Data. International Journal of Climatology, 28, 1821-1834. http://dx.doi.org/10.1002/joc.1676

[14] Ambreen, R., Qiu, X.F. and Ahmad, I. (2011) Distributed Modeling of Extraterrestrial Solar Radiation over the Rugged Terrains of Pakistan. Journal of Mountain Science, 8, 427-436. http://dx.doi.org/10.1007/s11629-011-2004-z

[15] Stefanovic, P. and Wiersema, G. (1985) Insolation from Digital Elevation Models for Mountain Habitat Evaluation. ITC Journal, 3, 177-186.

[16] Rich, P.M., Hetrick, W.A. and Saving, S.C. (1995) Modeling Topographic Influences on Solar Radiation: A Manual for the SOLARFLUX Model. Los Alamos National Laboratory Report LA-12989-M, Los Alamos.

[17] Zeng, Y., Qiu, X.F., Miao, Q.L. and Liu, C.M. (2003) Distribution of Possible Sunshine Durations over Rugged Terrains of China. Progress in Natural Science, 13, 761-764. http://dx.doi.org/10.1080/10020070312331344380 
Scientific Research Publishing (SCIRP) is one of the largest Open Access journal publishers. It is currently publishing more than 200 open access, online, peer-reviewed journals covering a wide range of academic disciplines. SCIRP serves the worldwide academic communities and contributes to the progress and application of science with its publication.

Other selected journals from SCIRP are listed as below. Submit your manuscript to us via either submit@scirp.org or Online Submission Portal.
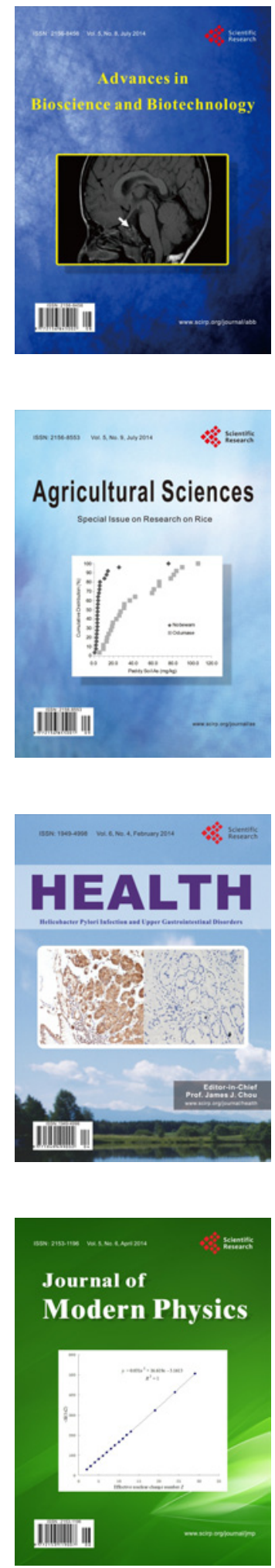
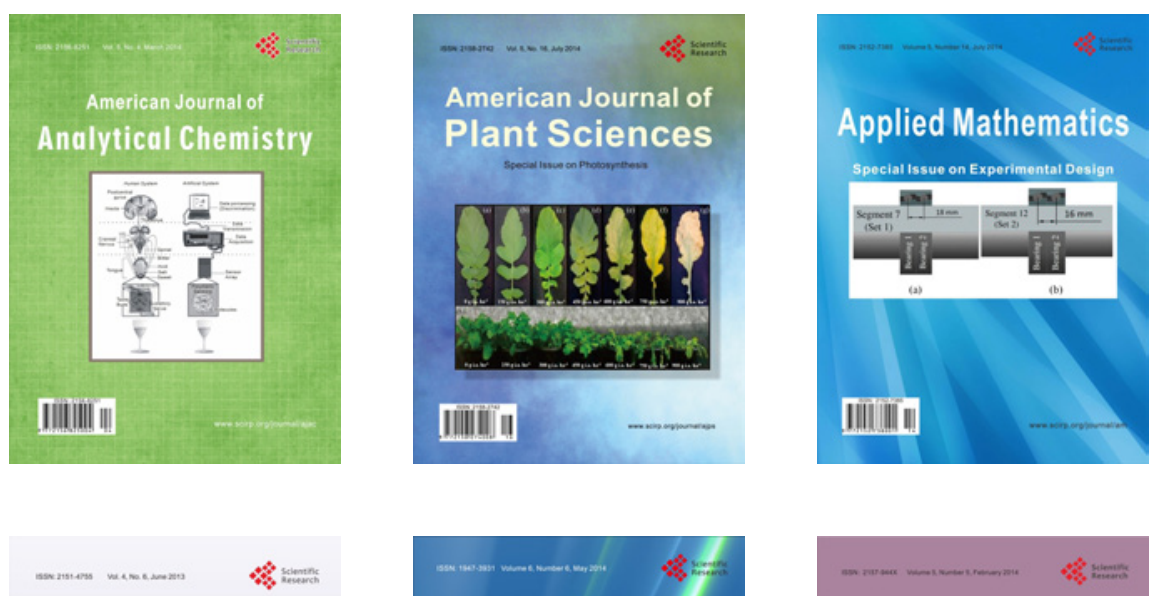

Creative Education
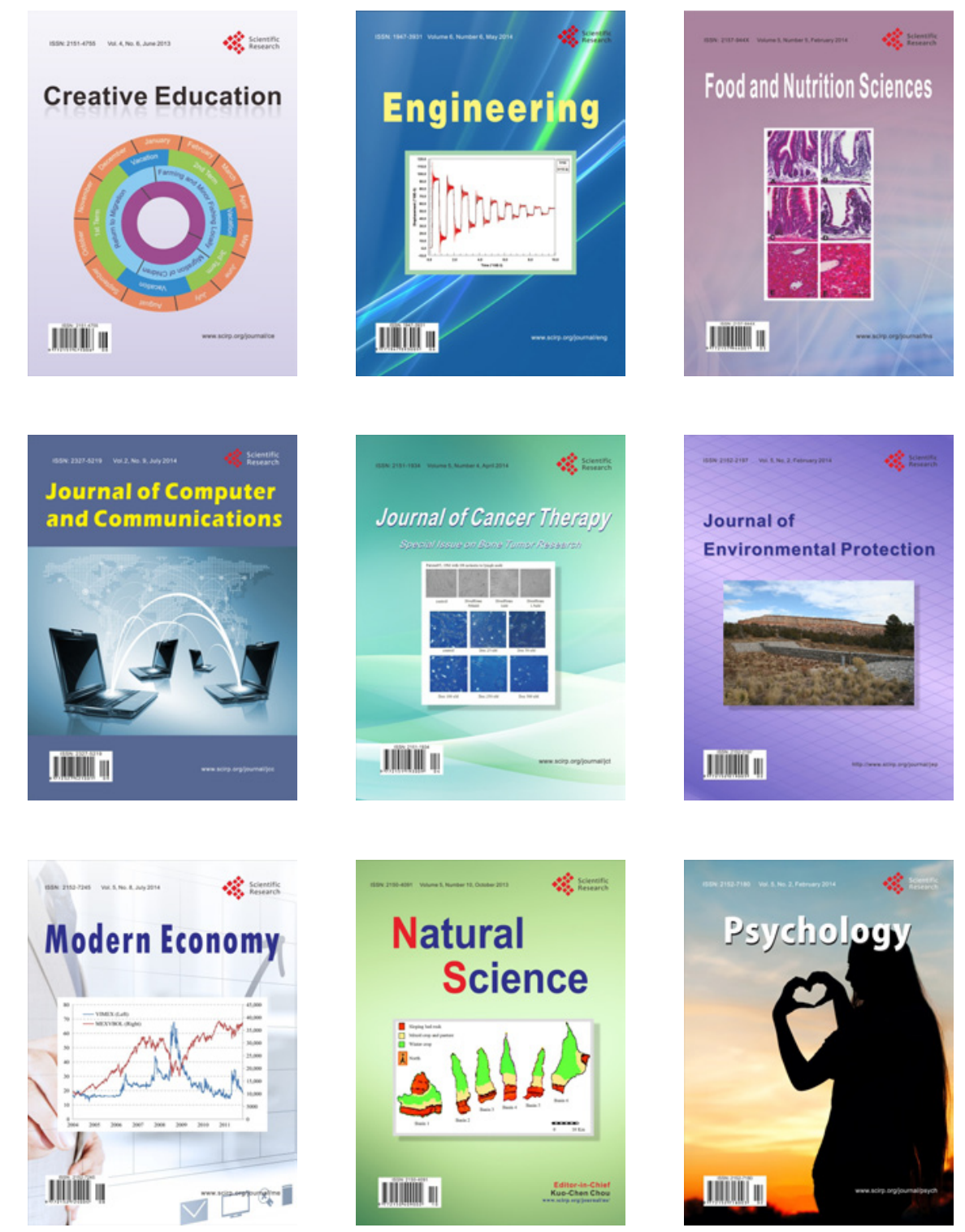